\title{
Proton Conductivity and Ethanol Permeability of Silane Treated Mordenite/Nafion Composite Membrane for Direct Ethanol Fuel Cell
}

\author{
R. Gokulakrishnan ${ }^{1 *}$, A. S. Perumal' and N. Manoharan ${ }^{2}$ \\ 'Department of Naval Architecture \& Offshore Engineering, AMET University, India; \\ krishfred@gmail.com, Perumal.as@ametuniv.ac.in \\ 2Directorresearch, AMET University, India; Directorresearch@ametuniv.ac.in
}

\begin{abstract}
Membrane is an important part in fuel cell. It should have high proton conductivity and low ethanol permeability to ensure high performance. Nafion membrane is commonly used For Direct Ethanol Fuel Cell (DEFC) since it has highest proton conductivity compared with other membranes
\end{abstract}

Keywords: DEFC, Ethanol Permeability, Mordenite Composite Membrane, Proton Conductivity, Silane Treatment

\section{Introduction}

Fuel cell has been developed for decades to use as alternative energy to fossil fuel. There are many types of fuel cell such as Proton Exchange Membrane Fuel Cell (PEMFC), Alkaline Electrolyte Fuel Cell (AEFC), Direct Methanol Fuel Cell (DMFC), medium and high temperature fuel cell ${ }^{1}$. The electric has produced from the electrochemical reaction depend on type of fuel cell. In this work, Direct Ethanol Fuel Cell (DEFC) was targeted for membrane improvement. Therefore, ethanol as liquid feed and nafion as membrane were used for permeability property study. There are many types of membrane used in fuel cell which are perfluorinated ionomers, partially fluorinated polymers, non-fluorinate membrane with aromatic backbone, acid-base membrane, and other types ${ }^{2}$. Nafion membrane contains tetrafluoroethylene as main chain with sulfonic group $\left(\mathrm{SO}_{3}^{-}\right)$as side chain as seen in Figure 1. This group act as an induce proton part to allow only proton, not electron, to pass through membrane $^{3}$. However, it spontaneously allows ethanol to pass through along with the proton. This phenomena result in the voltage drop in fuel cell. To improve the performance of the fuel cell, a lot of researches are being done by adding organic/inorganic materials or other material into Nafion membrane to reduce the ethanol crossover ${ }^{4-8}$.
In this study, mordenite was used to improve the fuel crossover. The structure of mordenite is shown in Figure 2. The advantage of mordenite are its stability up to $800^{\circ} \mathrm{C}$. It has low $\mathrm{Si} / \mathrm{Al}$ ratio which lead to being the hydrophilic molecule. So it is better in absorbing water than ethanol. It also has high ion exchange capacity and proton conductivity ${ }^{7-10}$. These properties can greatly assist the function of Nafion membrane in fuel cell. Therefore it is one of the best inorganic filling in this application. Moreover, 3-glycidoxyproply-trimethoxysilane (GPTMS) and 3-mercaptopropyl-trimethoxysilane (MPTMS) were used to treat mordenite before being incorporated in nafion to synthesis the composite membrane. The two silanes, as shown in Figure 3, have been widely used in this application as they can significantly improve the compatibility between the inorganic filler and the organic matrix ${ }^{7-8,11}$.

The objectives of this study were to investigate proton conductivity of Nafion/mordenite composite membrane for DEFC and to determine the mordenite treatment method to keep high conductivity with low ethanol permeability. The conductivity result of silaned treated mordenite composite membrane comparing with nontreated mordenite composite membrane, the recast nafion and commercial Nafion 117 performed in in-house equipment at 30,50 and $70^{\circ} \mathrm{C}$ is reported together with the permeability under the same condition. 


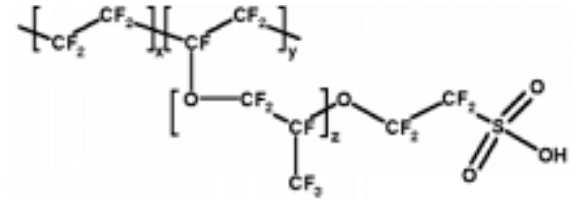

Figure 1. Structure of nafion membrane.

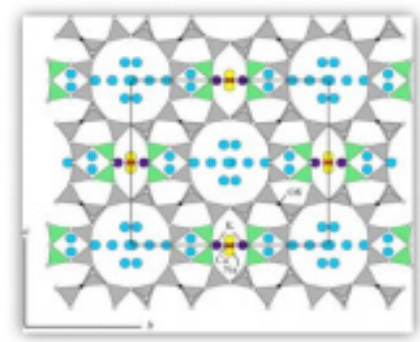

Figure 2. Structure of mordenite.

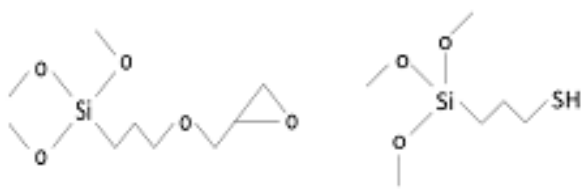

Figure 3. Structure of GMPTS (left) and MPTS (right).

\section{Methodology}

There are 8 parts of experiment held on this research work.

\subsection{Conductivity Test Cell Fabrication}

A conductivity test cell consists of two compartments, solution section for membrane conductivity measuring and temperature control section surrounded the solution section. Two platinum electrodes were attached at the top and the bottom of the solution side. One was fixed at the bottom and the other was free to be convenient for holding the membrane. During the experiment, $1 \mathrm{M}$ sulfuric acid solution was filled in and the load of 200 gram was used to maintain consistency of load. Water was used as a temperature control medium circulated by a pump connected to water bath. The probe from potentiostat was connected to the cell at both side of the electrode. Two probed method was used to measure the conductivity.

\subsection{Membrane Preparation}

The method for membrane treatment is shown as following: - Mordenite was grinded for 24 hours using ball mill to 3 micrometer in size. Then it was dried in oven at $40^{\circ} \mathrm{C}$ for 24 hours. - It was stirred in $1 \mathrm{M}$ sulfuric acid for 24 hours to protonate or proton functionalize into mordenite- $\mathrm{H}$ form. Then it was heated to $550^{\circ} \mathrm{C}$ for 5 hours. - One part of mordenite was dispersed in 5\%wt solution of GMPTS in dicholomethane and the other part wasdispersed in 5\%wt solution of MPTS in toluene under reflux condition. Both of them were stirred for 24 hours. For MPTS, treated mordenite was further oxidized by $30 \%$ wt $\mathrm{H}_{2} \mathrm{O}_{2}$ for 24 hours to change $-\mathrm{SH}$ into $-\mathrm{SO}_{3} \mathrm{H}$. Mordenite was dispersed in $20 \%$ wt Nafion solution in the mixture ofmethanol/ethanol/dimethylformamide(DMF). It was sonicated for 15 minutes and magnetic stirred for 15 minutes until 2 hours was reached. It was then put in vacuum oven at $80^{\circ} \mathrm{C}$ for 20 hours and followed by $150^{\circ} \mathrm{C}$ for 4 hours. - The composite membrane was cut to a suitable size for the test. It was boiled in deionised water for 10 minutes to ensure fully hydrated. It was then heated at $80^{\circ} \mathrm{C}$ for 30 minutes in a $5 \%$ vol solution of hydrogen peroxide to remove organic residues followed by washing in deionised water 2 times. - It was then boiled in a $1 \mathrm{M}$ sulphuric acid solution for 30 minutes to ensure that it was in acid form. Finally, it was boiled in deionised water for 10 minutes 3 times. The treated membrane was kept in deionised water until its use.

\subsection{Conductivity Test}

The conductivity was measured using AC Impedance Spectroscopy by 2-probe method. This method has been believed that it is suitable for measuring membrane resistance in transverse direction which is the direction in which the protons transport through the membrane ${ }^{12}$. The test was done in $1 \mathrm{M} \mathrm{H}_{2} \mathrm{SO}_{4}$ solution as a medium for membrane. The program was set at I MHz initial frequency and $100 \mathrm{MHz}$ at final frequency. The amplitude was $2 \mathrm{mV}$. The conductivity was calculated using the equation below:

$$
\sigma=\frac{d}{R_{m} A}
$$

where $\sigma$ is the conductivity $(\mathrm{S} / \mathrm{cm})$

$\mathrm{d}$ is the thickness of membrane $(\mathrm{cm})$

$\mathrm{R}_{\mathrm{m}}$ is the resistance of membrane $(\Omega)$

$\mathrm{A}$ is the surface area of electrode $\left(\mathrm{cm}^{2}\right)$

Two methods of conductivity test were performed in this study. First method is having the membrane immersed in the acid solution while measuring the resistance. The 
other method is measuring the membrane in air after heating in the acid solution to the required temperature. The membrane thickness at the same point was immediately measured after the conductivity measurement using micrometer. The values of conductivity at each condition from both methods were later compared.

\subsection{Ethanol Permeability}

In permeability test, a diffusion cell consists of two compartments, feed and permeate sides which are separated by the membrane. The feed side contains only water and the permeate side contains a mixture of methanol and water. Ethanol then diffuses across the membrane by concentration gradient between two sides. Finally, ethanol concentration in the permeate side is measured as a function of time.

The diffusion cell was connected to pumps and solution bottles and set up in the water bath. Then the temperature was adjusted in each experiment. The ethanol solution and deionised water were filled for each tank. Each experiment was done by collecting the sample at permeate side every 15 minutes until 2 hours and injecting the sample to Gas Chromatography (GC) for analysis the concentration of ethanol crossover ${ }^{8}$. Finally, the relationship of ethanol concentration versus period of time was plotted to determine the ethanol permeability.

\subsection{Water Uptake}

In water uptake measurement, firstly, the membrane was soak in deionized water for 24 hours. It was later weighted and recorded as mwet. After that it was dried in an oven at $100^{\circ} \mathrm{C}$ for 24 hours before another weighing and recording as mdry. The water uptake can be calculated from equation below;

$$
\text { Water uptake }(\%)=\frac{m_{w e t}-m_{d r y}}{m_{d r y}} \times 100
$$

where,

Veq is the volume of $\mathrm{NaOH}$ used in titration

$\mathrm{C}_{\mathrm{NaOH}}$ is the concentration of $\mathrm{NaOH}$

\subsection{Membrane Morphology}

All membranes were cross-sectioned and examined by Scanning Electron Microscopy (SEM) to study their thickness, distribution and adhesion between the particles and the polymer.

\subsection{Single Cell Testing}

Each membrane was hot press to make MEA using $4 \% \mathrm{Pt} / \mathrm{C}$ electrode catalyst and test in $1 \mathrm{M}$ methanol as fuel at $80^{\circ} \mathrm{C}$ to prove the performance or membrane under the fuel cell operating condition

\section{Results and Discussion}

Figure 4 shows the cross section of recasted Nafion membrane. The membranes have the thickness of 125-130 $\mu \mathrm{m}$. After the mordenites were added, two layer of membrane was formed as seen in Figure 5 to Figure 7. Figure 5

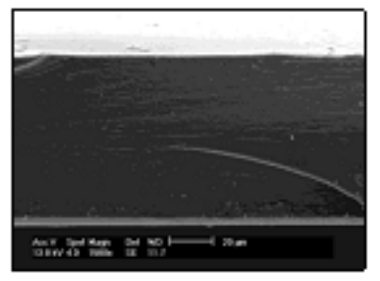

Figure 4. SEM image of recast Nafion membrane.
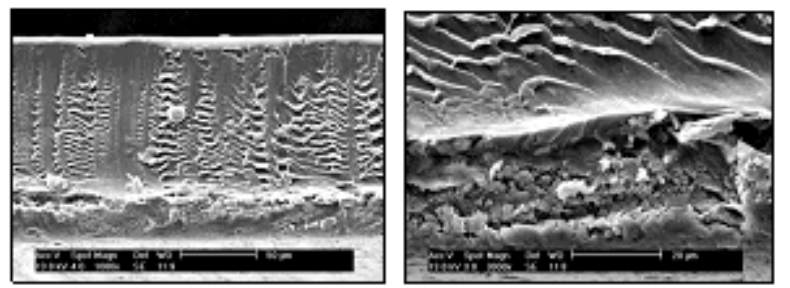

Figure 5. Cross-section of Naifon-Mor without without silane treatment (left)x1000(right) $\times 3000$.
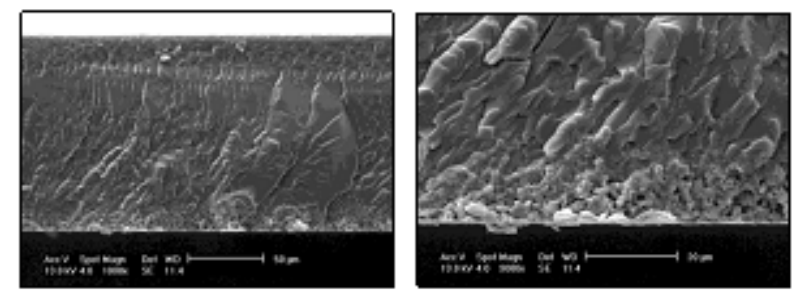

Figure 6. Cross-section of Naifon-Mor-MPTS(left)x 1000 (right) $\times 3000$
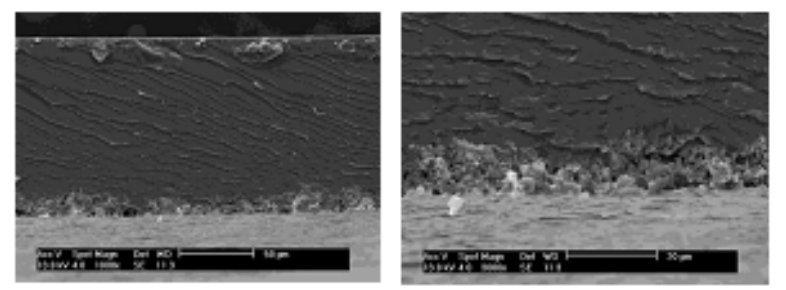

Figure 7. Cross-section of Nafion-Mor-GMPTS(left) x1000(right) x3000. 
shows the dispersion of unfunctionalizemordenite particles or so called MOR-H. It was found that there were some pin holes or membrane cracks that cause by a low compatibility between Nafion and mordenites. In Figure 6 and Figure 7, higher compatibility between Nafion and mordenite was found after functionalized with GMPTS and MPTS. This result suggests that theinteraction between mordenite and Nafion is strengthened in Naf/MOR-GMPTS and Naf/MOR-MPTS membranes ${ }^{8}$. The absence of pinholes is favorable for the reduction of the ethanol crossover. Thus, much better interfacial morphology is obtained.

From the experiment of ethanol permeability by diffusion cell, it was found that the ethanol permeability of commercial Nafion117 and recasted Nafion membrane are higher than that of composite membranes as seen in Table 1. This is due to mordenite incorporated in the polymer matrix can cause fuel transport channel leading to more difficult for fuel to cross over ${ }^{14,15}$. This can confirm that mordenite is one of the excellent ethanol barriers. The effect of mordenite modification on the ethanol crossover can also be clearly found. The silanes grafted on mordenite particles in Naf- MOR-GMPTS and Naf-MOR-MPTS composite membranes can enhanced the compatibility between the zeolite and the polymer as can be seen from the highpermeability of Naf-MOR over the silane treated mordenite composite membranes. This transitional phase created at the inorganic-polymer interface filled up the small voids and better in connection of the two phases together. It was found that Naf-MORMPTS composite membrane has a lower permeability than Naf-MOR-GMPTS composite membrane. This was due to the chain $-\mathrm{SO}_{3} \mathrm{H}$ group of MPTS on the modified Mordenite surface can form stronger interactions with the epoxy groups of Nafion than that in the case of epoxy group of GMPTS.

Table 1. Conductivity $(\mathrm{s} / \mathrm{cm})$ and permeability $\left(\mathrm{x} 10^{-6} \mathrm{~cm}^{2} / \mathrm{s}\right)$ at $2 \mathrm{~m} \mathrm{ETOH}$ of membranes at $30^{\circ} \mathrm{C}$ $50^{\circ} \mathrm{C}$ and $70^{\circ} \mathrm{C}$ measure with $\mathrm{H}_{2} \mathrm{SO}_{4}$ solution

\begin{tabular}{lcccccc}
\hline $\begin{array}{l}\text { Type of } \\
\text { membrane }\end{array}$ & \multicolumn{3}{c}{ Conductivity $(\mathrm{S} / \mathrm{cm})$} & \multicolumn{4}{c}{$\begin{array}{l}\text { Permeability } \\
\left(\mathbf{x 1 0}^{-6} \mathrm{~cm}^{2} / \mathrm{s}\right)\end{array}$} \\
\cline { 2 - 7 } & $\mathbf{3 0 ^ { \circ } \mathrm { C }}$ & $\mathbf{5 0 ^ { \circ } \mathrm { C }}$ & $\mathbf{7 0}^{\circ} \mathrm{C}$ & $\mathbf{3 0 ^ { \circ } \mathrm { C }}$ & $\mathbf{5 0}^{\circ} \mathrm{C}$ & $\mathbf{7 0 ^ { \circ } \mathrm { C }}$ \\
\hline Commercial & 0.0501 & 0.0483 & 0.0545 & 2.133 & 3.021 & 3.550 \\
Nafion117 & & & & & & \\
Recast Nafion & 0.0289 & 0.0328 & 0.0267 & 2.319 & 3.113 & 3.397 \\
Naf-Mor-MPTS & 0.0386 & 0.0365 & 0.0348 & 1.172 & 2.385 & 2.637 \\
Naf-Mor-GMPTS & 0.0335 & 0.0350 & 0.0301 & 1.466 & 2.545 & 3.034 \\
Naf-Mor & 0.0385 & 0.0369 & 0.0356 & 2.163 & 2.684 & 3.534 \\
\hline
\end{tabular}

The data of conductivity from Table 1 was plotted as in Figure 8. It can be seen that the commercial Nafion has the highest conductivity comparing to the recast and composite membranes. However, when comparing to only membranes synthesized in the lab, recasted Nafion has the lowest conductivity. The composite membranes have non-significant higher conductivity. The increasing in conductivity was calculated and showed in term of percentage increased from recasted Nafion as in Table 2. It is clearly seen that mordenite can slightly increase the proton conductivity of the composite membrane. This may be due to the structure of mordenite facilitates the transport of water through one side to the other side of the membrane $e^{9-11}$.

The data of conductivity and permeability can be analyzed in the form of ratio called 'selectivity'. It is the ratio of conductivity to permeability. The selectivity data of each membrane type is shown in Table 3. It was found that Naf-Mor-MPTS has the highest selectivity especially at $50^{\circ} \mathrm{C}$ and $70^{\circ} \mathrm{C}$. At $30^{\circ} \mathrm{C}$, the selectivity of Naf-MorMPTS and Naf-Mor-GMPTS were about the same but significantly higher than those without mordenites or silane treated mordenite composite membranes. This is due to the better compatibility between the mordenite and Nafion improved by silane agents.

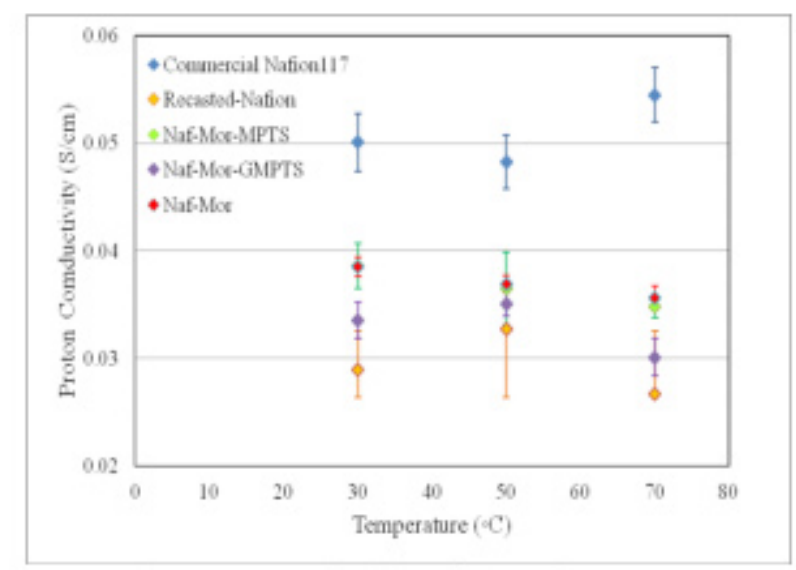

Figure 8. Proton conductivity $(\mathrm{S} / \mathrm{cm})$ at each temperature

Table 2. The increasing of conductivity of different membranes compared to Recast Nafion

\begin{tabular}{lcrc}
\hline Type & $\mathbf{3 0}{ }^{\circ} \mathrm{C}$ & $50^{\circ} \mathrm{C}$ & $70^{\circ} \mathrm{C}$ \\
\hline Naf-Mor-MPTS & $33.05 \%$ & $12.59 \%$ & $33.56 \%$ \\
Naf-Mor-GMPTS & $33.42 \%$ & $11.51 \%$ & $30.46 \%$ \\
Naf-Mor & $15.78 \%$ & $6.99 \%$ & $12.72 \%$ \\
\hline
\end{tabular}


Nevertheless, in this study, the other experiment was done in different ways to investigate the effect of testing methods during the conductivity measurement. The membrane was heated in the acid solution until its conductivity measurement. The membrane was taken out from the solution and immediately measured in air. Table 4 shows the conductivity measured in air. The commercial membrane was significant higher conductivity than others. However, comparing all recastedmembranes, the membrane recasted without addition of mordenite showed the lowest conductivity. With mordenite adding, the conductivity in all cases were about the same no matter there was any silane agents or not. Furthermore, the temperature change does not matter for all cases. This was the same trend but the values were lower than those tested in the acid solution in all cases. This can conclude that with mordenite adding, the conductivity property was about the same. These results were consistent to other works on proton conductivity of membranes ${ }^{7,8,13,16}$.

Table 5 shows water uptake and ion exchange capacity (IEC) of membranes. Water uptake indicates the ability of membrane to absorb water. The higher the water uptake, the higher the conductivity. Nevertheless, too high water uptake can lead to swelling of membrane and cause higher ethanol crossover. The ion exchange capacity indicate the number of sulfonic group per gram of dry membrane. The higher the IEC, the higher proton conductivity. From Table 5, the commercial Nafion has the highest water uptake and IEC which can lead to highest conductivity and crossover. This is consistant with the

Table 3. Selectivity of membranes at $30^{\circ} \mathrm{C} 50^{\circ} \mathrm{C}$ and $70^{\circ} \mathrm{C}$

\begin{tabular}{lccc}
\hline Type & $30^{\circ} \mathrm{C}$ & $50^{\circ} \mathrm{C}$ & $70^{\circ} \mathrm{C}$ \\
\hline Recast Nafion & 0.0125 & 0.0105 & 0.0079 \\
Naf-Mor-MPTS & 0.0224 & 0.0153 & 0.0132 \\
Naf-Mor-GMPTS & 0.0229 & 0.0138 & 0.0099 \\
Naf-Mor & 0.0178 & 0.0137 & 0.0101 \\
\hline
\end{tabular}

Table 4. Conductivity $(\mathrm{S} / \mathrm{cm})$ of membranes at $30^{\circ} \mathrm{C} 50^{\circ} \mathrm{C}$ and $70^{\circ} \mathrm{C}$ without $\mathrm{H}_{2} \mathrm{SO}_{4}$ solution during measurment

\begin{tabular}{llll}
\hline Type & $30^{\circ} \mathrm{C}$ & $50^{\circ} \mathrm{C}$ & $70^{\circ} \mathrm{C}$ \\
\hline Commercial Nafion 117 & 0.048 & 0.034 & 0.039 \\
Recast Nafion & 0.019 & 0.017 & 0.018 \\
Naf-Mor-MPTS & 0.026 & 0.021 & 0.027 \\
Naf-Mor-GMPTS & 0.023 & 0.018 & 0.024 \\
Naf-Mor & 0.029 & 0.020 & 0.026 \\
\hline
\end{tabular}

Table 5. Water uptake and ion exchange capacity of membranes

\begin{tabular}{lcc}
\hline Membrane type & Water Uptake (\%) & IEC $(\mathrm{mmol} / \mathrm{g})$ \\
\hline Commercial Nafion117 & 43.147 & 1.135 \\
Recast Nafion & 43.355 & 0.984 \\
Naf-Mor-MPTS & 43.087 & 0.994 \\
Naf-Mor-GMPTS & 42.887 & 0.992 \\
Naf-Mor & 38.214 & 1.011 \\
\hline
\end{tabular}

result from the conductivity and permeability. For others types of membranes, the values were not much significant different. The trend for two measurement methods was the same. However, the method with solution as measurement media was more suitable for transverse measurement ${ }^{12}$.

After the membrane characterization, it was finally pressed to make MEA and tested in fuel cell single stack at $80^{\circ} \mathrm{C}$ using $1 \mathrm{M} \mathrm{MeOH}$. The power density measured using different membrane was plot via current density (not shown here). It was found that Naf-Mor membrane had the lower power density. It was followed by recastedNafion membrane without any mordenite. The highest power density was found using Naf-Mor-MPTS and followed by Naf-Mor-GMPTS. The best one has almost about 2 times higher in power density than that of the worst one. This can be concluded that without any treatment of inorganic compound, the performance of composite membrane is the worst. And with the silane treatment on mordenite, the compatibility was improved as shown in the better performance was obtained ${ }^{7,8}$.

\section{Conclusion}

The conductivity of membrane is one of the importance properties in fuel cell application. Membrane modification is to improve the crossover of fuel often results in lower the conductivity of membrane itself. Decreasing the permeability while maintain or improve proton conductivity is required. In this work, silane treated mordenite in Nafion membranes were fabricated.

\section{References}

1. Lamimie J, Dicks A. Fuel cell system explained. John Wiley \& Sons; 2003.

2. Smitha B, Sridhar S, Khan AA. Solid polymer electrolyte membranes for fuel cell applications - a review. J Membr Sci. 2005; 259: 10-26. 
3. Haubold HG, Vad Th, Jungbluth H, Hiller P. Nano structure of NAFION: a SAXS study. Electrochimica Acta. 2002; 46: 1559-63.

4. Li C, et al. Casting Nafion-sulfonated organosilicananocomposite membranes used in direct methanol fuel cells. J Membr Sci. 2006; 272: 50-7.

5. Hwang M, Ha HY, Kim D. Zirconium meta-sulfonphenyl phosphonic acid-incorporated Nafiona ${ }^{\circledR}$ membranes for reduction of methanol permeability. J Membr Sci. 2008; 325(2): 647-52.

6. Hasani-Sadrabadi MM, et al. NafionA $\hat{A}^{\circledast / b i o-~ f u n c t i o n a l i z e d ~}$ montmorillonite nanohybrids as novel polyelectrolyte membranes for direct methanol fuel cells. J Power Sourc. 2009; 190(2): 318-21.

7. Li X, Robert EPL, Holmes SM. Evaluation of composite membranes for direct methanol fuel cells. J Power Sourc, $154,1,2006 ; 115-23$.

8. Yoonoo C, et al. Nafion/Mordenite composite membranes for improved direct methanol fuel cell performance. J Membr Sci. 2011;. 364-74.

9. Breck DW. Zeolite Molecular sieves: structure. chemistry and use. Wiley, New York: 1973.
10. Hibino T, Akimoto T, Iwahara H. Protonic conduction of mordenite-type zeolite. Solid State Ionics. 1993; 67: 71-6.

11. Nur $\mathrm{H}$, et al. Organosulfuric acid functionalized zeolite ZSM-5 as temperature tolerant proton conducting material. Int J Hydrogen Energ. 2012; 37: 12513-21

12. Woo Y, et al. Synthesis and characterization of sulfonated polyimide membranes for direct methanol fuel cell. J Membr Sci. 2003; 220: 31-45.

13. Kongkachuichay P, Pimprom P. Nafion/Analcime and Nafion/Faujasite composite membrane for polymer electrolyte membrane fuel cells. Chem Eng Res Des 2010; 8: 496-500.

14. Neburchilov V, et al. A reviw of polymer electrolyte membrane for direct methanol fuel cells. J Power Sourc. 2007; 169: 238.

15. Libby B, Smyrl WH, Cussler EL. Polymer-Zeolite composite membranes for direct methanol fuel cells. AIChE J. 2003; 49: 991-1001.

16. Holmberg BA, Wang X, Yan Y. Nanocomposite fuel cell membranes based on nafion and acid functionalized zeolite beta nanocrystals. J Membr Sci. 2008; 320; 86-92. 